\title{
Hidrolisados cárneos na alimentação do surubim do Iguaçu (Steindachneridion melanodermatum)*
}

\section{Meat hydrolysates in feeding of Iguaçu catfish (Steindachneridion melanodermatum)}

\author{
Vanessa Lewandowski, ${ }^{* *}$ Junior Antonio Decarli, ${ }^{* * *}$ Fábio de Araújo Pedron, ${ }^{* * *}$ Aldi Feiden, ${ }^{* *}$ Altevir Signor, ${ }^{* *}$ \\ Wilson Rogério Boscolo**
}

\begin{abstract}
Resumo
O presente estudo objetivou verificar a influência da inclusão de diferentes fontes de hidrolisados cárneos na alimentação do surubim do Iguaçu (Steindachneridion melanodermatum). Para a realização do experimento, foram utilizados 256 juvenis de surubim com peso inicial médio de $23,54 \pm 0,83 \mathrm{~g}$ e comprimento total médio de $13,26 \pm 0,22 \mathrm{~cm}$. Realizou-se um delineamento em blocos ao acaso com quatro tratamentos e quatro repetições. Foram formuladas 4 dietas isoproteicas e isoenergéticas. Foram incluídas às dietas, hidrolisados de fígado suíno, carcaça de tilápia e sardinha em uma proporção de 60, 40 e $60 \mathrm{~g} / \mathrm{kg}$ de ração, respectivamente. $\mathrm{Na}$ dieta controle não houve acréscimo de hidrolisado. Ao final do experimento, determinaram-se os parâmetros de desempenho zootécnico, hematológicos e composição química da carcaça. Os dados referentes aos parâmetros avaliados foram submetidos à análise de variância de efeitos principais e posteriormente ao teste de Tukey ao nível de $5 \%$ de probabilidade através do programa estatístico Statisttics 7.0.Em relação aos parâmetros zootécnicos, as dietas testadas influenciaram significativamente $(P<0,05)$ os valores de peso final, comprimento final e conversão alimentar aparente. Os parâmetros bioquímicos mensurados e a composição de carcaça não diferiram estatisticamente $(P>0,05)$. A inclusão de hidrolisado de fígado suíno e de sardinha em dietas melhora o peso, ganho de peso comprimento e conversão alimentar do surubim do luaçu, e não afeta os parâmetros bioquímicos do sangue, bem como sua composição química da carcaça. Dessa forma, a utilização de hidrolisados em rações para peixes pode ser uma alternativa para aumentar o desempenho zootécnico dos animais.
\end{abstract}

Palavras-chave: espécie nativa, nutrição, desempenho zootécnico.

\begin{abstract}
The present work aimed to verify the influence of different sources of meat hydrolysates in the feed of lguaçu catfish (Steindachneridion melanodermatum). To perform the experiment, we used 256 catfish juveniles with initial average weight of $23,54 \pm 0,83 \mathrm{~g}$ and total average length of $13,26 \pm 0,22 \mathrm{~cm}$. We realized a randomized block design with four treatments and four replications. Four diets were formulated being isoproteics and isocalorics. We included hydrolysates of swine liver, tilapia carcass and sardine in proportion of 60,40 and $60 \mathrm{~g} / \mathrm{kg}$ of the diet, respectively. In the control diet there was not hydrolysate. At the end of experiment, we determined the performance, hematologic and carcass chemical composition parameters. The data were submitted to main effects variance analysis through statistic program Statisttics 7.0. The diets tested influenced significantly $(P<0,05)$ the values of final weight, final length and feed conversion. The biochemical and carcass chemical composition parameters did not differ statistically $(P>0,05)$. The inclusion of swine liver and sardine hydrolysates in the diets improve the weight, weight gain, length and feed conversion of Iguaçu catfish and does not affect the blood biochemical parameters as well as their carcass chemical composition. Thus, the use of hydrolysates in diets for fish can be an alternative to increase the animal performance.
\end{abstract}

Keywords: Native species, nutrition, performance.

\section{Introdução}

O Brasil apresenta uma proporção significante da ictiofauna Sulamericana (Rosa e Menezes, 1996). Nesse contexto, evidenciase a bacia hidrográfica do rio Iguaçu, a qual localiza-se na região sudeste da América do Sul e caracteriza-se por ser o maior complexo hidrográfico do estado do Paraná. Segundo Zawadzki et al. (1999), essa bacia abriga um elevado número de espécies de peixes endêmicas, fato este que pode ter sido favorecido pelo isolamento geográfico provocado pelas Cataratas do Iguaçu (Baumgartner et al., 2012).

\footnotetext{
*Recebido em 29 de agosto de 2013 e aceito em 8 de dezembro de 2013.

**Universidade Estadual do Oeste do Paraná - Campus Toledo, Toledo-PR, Brasil. Vanessa.engpesca@hotmail.com.

***Universidade Estadual Paulista - Campus Botucatu, Botucatu, SP, Brasil.

****Universidade Federal do Pampa - Campus Uruguaiana, Uruguaiana-RS, Brasil.
} 
O surubim do Iguaçu (Steindachneridion melanodermatum), descrito por Garavello (2005), caracteriza-se por ser uma das espécies endêmicas que habitam essa bacia hidrográfica, sendo encontrado apenas no baixo Iguaçu (Severi e Cordeiro, 1994).

A boa qualidade de carne, ausência de espinhos intramusculares e um bom rendimento de carcaça, fazem com que o surubim do Iguaçu seja uma espécie com grande potencial de cultivo (Sant'anna, 2009).

O crescente interesse pela produção de peixes nativos realça a necessidade da realização de estudos científicos relacionados com o desempenho zootécnico desses animais. Pesquisas vinculadas à nutrição dos mesmos apresentam grande importância, visto que suas exigências nutricionais podem sofrer variação em relação ao hábito alimentar e fase de criação entre espécies e entre indivíduos (Cotan et al., 2006).

Em relação à alimentação artificial de peixes, destacam-se os hidrolisados proteicos, os quais podem ser obtidos pela ação de enzimas proteolíticas sob circunstâncias aceleradas de digestão (Ritchie e Mackie, 1982). O processo de hidrólise enzimática tem sido utilizado com a finalidade de melhorar propriedades físicas, químicas e funcionais dos alimentos, sem prejudicar seu valor nutritivo, melhorando, particularmente, as características de absorção das proteínas (Pacheco et al., 2005). Com isso, aumentou-se significativamente o interesse na utilização de enzimas a fim de transformar resíduos de processamento de produtos de origem vegetal e animal (Onodenalore e Shahidi, 1996), entre eles peixes ou espécies subutilizadas em concentrados de proteínas para ingredientes alimentícios (Choi et al., 2009).

Dessa forma, o presente estudo objetivou verificar a influência da inclusão de diferentes fontes de hidrolisados cárneos na alimentação do surubim do Iguaçu (Steindachneridion melanodermatum).

\section{Materiais e métodos}

O experimento foi realizado na área aquícola do reservatório da Usina Hidrelétrica Governador José Richa (Salto Caxias - Rio Iguaçu), pertencente ao Centro de Difusão de Tecnologias do Rio Iguaçu (CDT-Iguaçu), localizado no município de Boa vista da Aparecida, Paraná. O período de experimentação foi de 27 de abril de 2011 a 7 de julho de 2011, totalizando 72 dias.

Foram utilizados 256 juvenis de surubim com peso inicial médio de $23,54 \pm 0,83 \mathrm{~g}$ e comprimento total médio de $13,26 \pm 0,22 \mathrm{~cm}$, distribuídos em 16 hapas de $0,3 \mathrm{~m}^{3}$ de volume útil, acondicionadas em quatro tanques-rede de $4 \mathrm{~m}^{3}$. Realizou-se um delineamento em blocos ao acaso com quatro tratamentos e quatro repetições, sendo que cada bloco continha todos os tratamentos.
As rações foram confeccionadas na Fábrica de Ração do Grupo de Estudos de Manejo na Aquicultura (GEMAq) da Universidade Estadual do Oeste do Paraná, em Toledo (PR). Os alimentos foram moídos em moinho tipo "martelo", misturados e extrusados em máquisa extrusora Ex-Micro ${ }^{\circledR}$,secas em estufa de ventilação forçada a $55^{\circ} \mathrm{C}$ por 24 horas e, após resfriamento, acondicionadas em sacos em condições refrigeradas. As dietas foram formuladas de forma a serem isoprotéicas (30\% de PB) e isoenergéticas $(2800 \mathrm{Kcal} / \mathrm{Kg}$ de energia digestível) (Tabela 1). Os animais foram alimentados duas vezes ao dia ( $8 \mathrm{~h} \mathrm{e} \mathrm{17h)}$ até a saciedade aparente.

Tabela 1: Formulação das dietas para o surubim do Iguaçu

\begin{tabular}{lcccc}
\hline \multirow{2}{*}{ Ingredientes (g/Kg) } & \multicolumn{3}{c}{ Fontes de hidrolisados proteicos } \\
\cline { 2 - 5 } & Dieta controle & $\begin{array}{c}\text { Hidrolisado } \\
\text { fígado suíno }\end{array}$ & $\begin{array}{c}\text { Hidrolisado } \\
\text { de tilápia }\end{array}$ & $\begin{array}{c}\text { Hidrolisado } \\
\text { de sardinha }\end{array}$ \\
\hline Farelo de soja & 495,00 & 460,00 & 480,00 & 460,00 \\
Farinha vísceras de aves & 90,00 & 60,00 & 80,00 & 65,00 \\
Milho & 194,80 & 194,80 & 194,80 & 194,80 \\
Arroz quirera & 200,00 & 200,00 & 200,00 & 200,00 \\
Hidrolisado & 0,00 & 60,00 & 40,00 & 60,00 \\
Óleo de soja & 15,00 & 20,00 & 0,00 & 15,00 \\
Premix vitamínico e mineral & 5,00 & 5,00 & 5,00 & 5,00 \\
BHT ${ }^{2}$ & 0,20 & 0,20 & 0,20 & 0,20 \\
\hline Total & $\mathbf{1 0 0 0 , 0 0}$ & $\mathbf{1 0 0 0 , 0 0}$ & $\mathbf{1 0 0 0 , 0 0}$ & $\mathbf{1 0 0 0 , 0 0}$ \\
\hline Nutrientes (g/Kg) & & & & \\
\hline Proteína bruta & 300,00 & 300,00 & 300,00 & 300,00 \\
Energia digestível (Kcal/Kg) & 2801,00 & 2821,00 & 2813,00 & 2798,00 \\
Extrato etéreo & 40,00 & 43,00 & 44,00 & 40,00 \\
Fibra bruta & 28,00 & 26,00 & 27,00 & 26,00 \\
Matéria mineral & 44,00 & 50,00 & 48,00 & 52,00 \\
Cálcio & 23,00 & 23,00 & 23,00 & 23,00 \\
Fósforo & 15,00 & 15,00 & 15,00 & 15,00 \\
\hline & & & &
\end{tabular}

Foram incluídas às dietas, hidrolisados de fígado suíno, carcaça de tilápia e sardinha na proporção de 60,40 e $60 \mathrm{~g} / \mathrm{kg}$ de ração, respectivamente. Na dieta controle não houve acréscimo de hidrolisado. A inclusão de menor quantidade do hidrolisado de carcaça de tilápia baseou-se no fato de que o mesmo apresenta maior percentual de gordura em relação aos demais hidrolisados, impossibilitando a extrusão da ração (Tabela 2).

Tabela 2: Composição química da matéria natural dos diferentes hidrolisados cárneos

\begin{tabular}{lccc}
\hline Hidrolisado protéico & Fígado suíno & Tilápia & Sardinha \\
\hline Proteínas(\%) & 14,80 & 8,80 & 12,21 \\
Lipídeos (\%) & 1,32 & 13,39 & 1,55 \\
Matéria mineral (\%) & 5,59 & 4,52 & 5,21 \\
Umidade (\%) & 73,69 & 71,51 & 76,10 \\
\hline
\end{tabular}


Os parâmetros de qualidade da água do experimento foram de $3,70 \pm 0,5 \mathrm{~m}, 7,43 \pm 1,2,5,48 \pm 1,1 \mathrm{mg} \cdot \mathrm{L}^{-1}, 6,12 \pm 1,4 \mu \mathrm{s} . \mathrm{cm}^{-1}$ e $20,0 \pm 2,0^{\circ} \mathrm{C}$, para transparência, $\mathrm{pH}$, oxigênio dissolvido, condutividade elétrica e temperatura, respectivamente. A temperatura e a transparência da água foram verificadas diariamente. Os demais parâmetros físico-químicos da água $(\mathrm{pH}$, oxigênio dissolvido e condutividade elétrica) foram mensurados em três repetições durante o desenvolvimento do ensaio (início, meio e fim).

Ao final do período experimental, os animais permaneceram em jejum por 24 horas, para o esvaziamento do trato gastrointestinal. Posteriormente, foram coletados dois peixes de cada unidade experimental para a coleta de sangue. Para tanto os animais foram anestesiados com benzocaina (250 mg. $\left.\mathrm{L}^{-1}\right)$, sendo em seguida realizada a coleta de $2,0 \mathrm{ml}$ de sangue de cada animal, através de punção caudal. Em seguida, as amostras de sangue foram centrifugadas a $2500 \mathrm{rpm}$ para obtenção do soro e congeladas a $-20^{\circ} \mathrm{C}$. Então, utilizando o método enzimáticocolorimétrico foram determinadas as dosagens de colesterol, triglicerídeos e proteínas totais utilizando kits específicos Gold Analisa Diagnóstica.

Após a coleta de sangue, todos os peixes foram insensibilizados em água e gelo, possibilitando a realização da biometria final. Os parâmetros de desempenho produtivo avaliados foram peso final, comprimento final, ganho de peso (Peso final - peso inicial), conversão alimentar aparente (Consumo de ração/ganho de peso) e taxa de sobrevivência. Também foram mensurados os valores rendimento de carcaça, índice hepatossomático e gordura visceral.

As análises de composição química (umidade, proteína bruta, extrato etéreo e matéria mineral) foram efetuadas segundo a metodologia descrita na AOAC (2005), sendo utilizados dois peixes de cada unidade experimental.

Os dados referentes aos parâmetros avaliados foram submetidos à análise de variância de efeitos principais e posteriormente ao teste de Tukey ao nível de $5 \%$ de probabilidade através do programa estatístico Statisttics 7.0. dietas contendo diferentes fontes de hidrolisados proteicos, constando valores significativamente maiores para os animais arraçoados com dietas contendo apenas hidrolisados de peixes, quando comparados aos alimentados com hidrolisados de peixe e carne. Contrastando com esses resultados, Goes et al.(2010) e Fries et al. (2011) não observaram diferenças significativas no desempenho zootécnico de piavuçu e kinguios, respectivamente, alimentados com dietas contendo diferentes fontes de hidrolisados.

Contudo, avaliando-se apenas níveis de inclusão de hidrolisados de peixes em dietas, pesquisas relatam efeitos positivos em relação ao aumento de peso dos animais. Tang et al. (2008) observaram um aumento de peso para o Pseudosciaena crocea alimentado com rações contendo 10 e 15\% de hidrolisados de peixe. Da mesma forma, constatou-se uma elevação significativa nos valores de peso final para o salmão do atlântico alimentado com dietas contendo hidrolisado de peixe (Berge e Storebakken, 1996; Refstie et al., 2004; Hevroy et al., 2005). Aksness et al. (2006) e Aguila et al. (2007) também verificaram um aumento de peso com a inclusão do mesmo hidrolisando na alimentação de Gadus morhua e Octopus maya, respectivamente.

No presente estudo, pôde-se observar que, apesar das dietas incrementadas com hidrolisado terem proporcionado maior valor de peso final, ganho de peso e comprimento final, quando comparado com os resultados obtidos pelo fornecimento da dieta controle, apenas os surubins alimentados com hidrolisado de fígado suíno apresentaram valores significativamente mais vantajosos para o peso final e ganho de peso e, juntamente com os alimentados com a dieta contento hidrolisado de sardinha, demonstraram maior comprimento final. Em relação à conversão alimentar, o melhor valor foi verificado nos peixes alimentados com a dieta contendo hidrolisado de sardinha.

Comparando-se os resultados de peso final, ganho de peso e conversão alimentar, nota-se que, embora os peixes alimentados com dieta contendo hidrolisado de sardinha terem apresentado melhor conversão alimentar, a ingestão da mesma foi inferior às demais dietas, provocando consequentemente menores valores

\section{Resultados e discussão}

As análises de variância revelaram que as dietas testadas influenciaram significativamente $(P<0,05)$ os valores de peso final, comprimento final, ganho de peso e conversão alimentar aparente. Entretanto, os surubins avaliados não demonstraram alterações $(P<0,05)$ em relação à taxa de sobrevivência, rendimento de carcaça, índice hepatossomático e gordura visceral (Tabela 3).

Estudos científicos descrevem diferentes resultados em relação à inclusão de hidrolisados cárneos na alimentação de algumas espécies de peixes. Carvalho et al. (1997) observaram diferenças em relação ao peso e comprimento final de larvas de carpa alimentadas com
Tabela 3: Desempenho zootécnico dos surubins do Iguaçu alimentados com dietas acrescidas de diferentes fontes de hidrolisados cárneos

\begin{tabular}{lcccc}
\hline \multirow{2}{*}{ Parâmetros } & \multicolumn{4}{c}{ Tratamentos } \\
\cline { 2 - 5 } & Dieta controle & $\begin{array}{c}\text { Hidrolisado } \\
\text { fígado suíno }\end{array}$ & $\begin{array}{c}\text { Hidrolisado } \\
\text { de tilápia }\end{array}$ & $\begin{array}{c}\text { Hidrolisado } \\
\text { de sardinha }\end{array}$ \\
\hline Peso final (g) & $54,47 \pm 2,14^{\mathrm{b}}$ & $61,97 \pm 2,11^{\mathrm{a}}$ & $57,20 \pm 2,98^{\mathrm{ab}}$ & $58,23 \pm 2,78^{\mathrm{ab}}$ \\
Comprimento final (cm) & $16,46 \pm 0,17^{\mathrm{c}}$ & $17,37 \pm 0,26^{\mathrm{a}}$ & $16,80 \pm 0,06^{\mathrm{bc}}$ & $16,94 \pm 0,27^{\mathrm{ab}}$ \\
Ganho de peso (g) & $31,55 \pm 1,74^{\mathrm{b}}$ & $38,03 \pm 2,64^{\mathrm{a}}$ & $33,81 \pm 3,25^{\mathrm{ab}}$ & $34,32 \pm 2,33^{\mathrm{ab}}$ \\
Sobrevivência (\%) & $96,87 \pm 3,60$ & $95,31 \pm 5,98$ & $95,31 \pm 3,12$ & $92,18 \pm 3,12$ \\
Conversão alimentar aparente & $1,74 \pm 0,28^{\mathrm{b}}$ & $1,96 \pm 0,11^{\mathrm{b}}$ & $1,93 \pm 0,13^{\mathrm{b}}$ & $1,32 \pm 0,08^{\mathrm{a}}$ \\
Rendimento de carcaça (\%) & $87,05 \pm 2,76$ & $85,72 \pm 1,48$ & $84,68 \pm 2,47$ & $86,06 \pm 2,82$ \\
Índice hepatossomático & $2,46 \pm 0,64$ & $2,32 \pm 0,32$ & $2,55 \pm 0,59$ & $2,55 \pm 0,59$ \\
\hline Gordura visceral (\%) & $5,13 \pm 1,48$ & $5,14 \pm 1,39$ & $3,73 \pm 0,76$ & $4,68 \pm 1,61$ \\
\hline
\end{tabular}


de peso final e ganho de peso. Isso pode ser explicado pelo fato de que além do processo de fabricação, os hidrolisados são diretamente influenciados pela matéria-prima, como constatado por Neves et al. (2004), os quais testaram hidrolisados com diferentes fontes de pescado e, observaram variações em relação ao grau de hidrólise, distribuição do peso molecular e perfil de aminoácidos. Essas variações alteram as propriedades físicas e químicas dos produtos finais, como por exemplo a palatabilidade, que é um importante parâmetro na ingestão de alimento (Luo et al., 2006)

Segundo Carvalho et al. (1997), os hidrolisados proteicos aumentam os índices de desempenho zootécnico dos animais, uma vez que, seu elevado teor de digestibilidade (Berge e Storebakken, 1996) e palatabilidade (OlivaTeles et al., 1999; Aguila et al., 2007) provocam um aumento de consumo da ração e, consequentemente, elevam os valores de ganho de peso e crescimento (Berge e Storebakken, 1996). O melhoramento da qualidade física da ração causado pela inclusão de hidrolisado (Martone et al., 2005) deve-se ao efeito do tratamento enzimático que degrada as proteínas em peptídeos menores e aminoácidos livres (Bhaskar, 2007), o que facilita a absorção dessas moléculas pelas células epiteliais do intestino (Bakke et al., 2010).

Os valores de rendimento de carcaça dos surubins analisados nesse experimento foram mais elevados do que os encontrados por Crepaldi et al. (2008) e Burket et al. (2008) para o Pseudoplatystoma sp. e equivalentes aos encontrados por Boscolo et al. (2010) e Reidel et al. (2010), para a tilápia-do-nilo e jundiá, respectivamente. $\mathrm{O}$ bom índice do rendimento de carcaça é uma característica que torna os surubins propícios ao processamento, que, segundo Burket et al. (2008), é um dos critérios observados na escolha de uma espécie para o cultivo. Crepaldi et al. (2006) afirmam que, além de um bom rendimento de carcaça, o surubim apresenta características zootécnicas e organolépticas favoráveis, atributos que contribuem com o sucesso da produção.

O índice hepatossomático e a gordura visceral não foram alterados pelos distintos tratamentos. Os valores do índice hepatossomático encontrados no presente experimento foram semelhantes aos encontrados por Boscolo et al. (2010) e Feiden et al. (2010) para juvenis de tilápia-do-nilo e de jundiá, respectivamente. Segundo Burket et al. (2008), o fígado do surubim apresenta um sabor característico e é apreciado por uma grande parte da população, permitindo assim seu processamento, constituindo em mais uma forma de agregação de valor desse peixe.

Os parâmetros sanguíneos mensurados (colesterol, triglicerídeos e proteínas totais) não diferiram estatisticamente entre si $(P>0,05)$ (Tabela 4). Todavia, a determinação dos parâmetros bioquímicos é importante para o conhecimento do metabolismo dos peixes em função das alterações da dieta, além de servirem como indicativos de estado nutricional e de saúde (Kumar et al., 2010). dietas acrescidas de diferentes fontes de hidrolisados cárneos

\begin{tabular}{lcccc}
\hline \multirow{2}{*}{ Parâmetros } & \multicolumn{4}{c}{ Tratamentos } \\
\cline { 2 - 5 } & Dieta controle & $\begin{array}{c}\text { Hidrolisado } \\
\text { fígado suíno }\end{array}$ & $\begin{array}{c}\text { Hidrolisado } \\
\text { de tilápia }\end{array}$ & $\begin{array}{c}\text { Hidrolisado de } \\
\text { sardinha }\end{array}$ \\
\hline Colesterol & $167,17 \pm 38,6$ & $173,10 \pm 76,4$ & $165,83 \pm 16,2$ & $153,44 \pm 41,9$ \\
Triglicerídeos & $889,08 \pm 333,1$ & $1032,28 \pm 283,1$ & $975,47 \pm 363,3$ & $757,87 \pm 395,9$ \\
Proteínas totais & $3,45 \pm 1,58$ & $4,58 \pm 0,89$ & $4,85 \pm 0,52$ & $3,82 \pm 1,57$ \\
\hline
\end{tabular}

Tabela 5: Valores de composição de carcaça dos surubins do Iguaçu alimentados com dietas acrescidas de diferentes fontes de hidrolisados cárneos

Segundo Öner et al. (2008), o colesterol é um componente estrutural essencial das membranas e o precursor de todos os esteroides hormonais e o seu aumento no plasma sanguíneo pode ser um bom indicador de estresse ambiental. No presente experimento não foram verificados valores significativamente diferentes de colesterol nos peixes em relação aos tratamentos, podendo afirmar que todos os peixes do experimento mantiveram-se no mesmo nível de estresse ambiental.

Em relação aos valores de triglicerídeos e proteínas totais, pode-se afirmar que as dietas não provocaram alteração no metabolismo lipídico e proteico dos peixes, uma vez que os triglicerídeos e as proteínas totais podem ser utilizados como indicadores desses processos metabólicos (Öner et al., 2008).

\begin{tabular}{lcccc}
\hline \multirow{2}{*}{ Parâmetros } & \multicolumn{4}{c}{ Tratamentos } \\
\cline { 2 - 5 } & Dieta controle & $\begin{array}{c}\text { Hidrolisado } \\
\text { fígado suíno }\end{array}$ & $\begin{array}{c}\text { Hidrolisado } \\
\text { de tilápia }\end{array}$ & $\begin{array}{c}\text { Hidrolisado } \\
\text { de sardinha }\end{array}$ \\
\hline Umidade (\%) & $68,06 \pm 1,53$ & $67,98 \pm 1,53$ & $69,73 \pm 0,65$ & $67,94 \pm 1,00$ \\
Proteína (\%) & $16,02 \pm 1,00$ & $16,28 \pm 0,52$ & $12,34 \pm 1,86$ & $17,44 \pm 0,24$ \\
Lipídeos (\%) & $13,31 \pm 2,03$ & $11,40 \pm 0,96$ & $10,55 \pm 0,21$ & $11,44 \pm 0,88$ \\
Cinzas (\%) & $3,62 \pm 0,21$ & $3,60 \pm 0,20$ & $3,33 \pm 0,18$ & $3,39 \pm 0,21$ \\
\hline
\end{tabular}

Médias estatisticamente não significativas observadas pelo teste de Tukey $(P>0,05)$

Os valores de composição de carcaça não diferiram estatisticamente $(p>0,05)$ entre os diferentes tratamentos testados (Tabela 5).

Os resultados observados corroboram com Nascimento et al. (2008), os quais não observaram diferença estatística em relação a composição de carcaça de surubins (Pseudoplatystoma corruscans) alimentados com hidrolisados proteicos de cabeça de matrinxã e de tambaqui. 
Segundo Rahman et al. (1995), os peixes gordos são aqueles que apresentam mais do que $10 \%$ de gordura em sua composição corporal. Desta forma, os resultados obtidos quanto ao teor de lipídeos na carcaça indicam que o surubim do Iguaçu pode ser considerado um peixe gordo. Essa classificação do peixe em relação ao teor de gordura mostra-se importante, uma vez que ela pode influenciar no desempenho produtivo, na aceitação pelo mercado consumidor, além de alterar a palatabilidade da carne (Santos et al., 2001).

\section{Referências}

AGUILA, J.; CUZON, G.; PASCUAL, C.; DOMINGUES, P.M.; GAXIOLA, G.; SÁNCHEZ, A.; MALDONATO, T.; ROSAS, C. The effects of fish hydrolysate (CPSP) level on Octopus maya (Voss and Solis) diet: Digestive enzyme activity, blood metabolites, and energy balance. Aquaculture, v. 273, p. 641-655, 2007.

AOAC. Official methods of analysis of the Association Analytical Chemists. 18. ed. Gaithersburg, Maryland, 2005.

AKSNES, A.; HOPE, B.; HOSTMARK, O.; ALBREKTSEN, S. Inclusion of size fractionated fish hydrolysate in high plant protein diets for Atlantic cod, Gadus morhua. Aquaculture, v. 261, p. $1102-$ 1110, 2006.

BAUMGARTNER, G.; PAVANELLI, C.S.; BAUMGARTNER, D.; BIFI, A.G.; DEBONA, T.; FRANA, V.A. Peixes do Baixo Rio Iguaçu. Maringá: Eduem, 2012, 203 p.

BAKKE, S.; JORDAL, A.O.; GÓMEZ-REQUENI, P.; VERRI, T.; KOUSOULAKI, K.; AKSNES, A.; RONNESTAD, I. Dietary protein hydrolysates and free amino acids affects the spatial expression. Of peptide transporter PepT1 in the digestive tract of atlantic cod (Gadus morhua). Comparative Biochemistry and Physiology, Part B, v. 156, p. 48-55, 2010.

BERGE, G.M.; STOREBAKKEN, T. Fish protein hydrolyzate in starter diets for Atlantic salmon (Salmo salar) fry. Aquaculture, v. 145, p. 205-212, 1996.

BHASKAR, N.; MODI, V.K.; GOVINDARAJU, K. RADHA, C.; LALITHA, R.G. Utilization of meat industry by products: Protein hydrolysate from sheep visceral mass. Bioresource Technology, v. 98, p. 388-394, 2007.

BOSCOLO, W.R.; HAYASHI, C.; FEIDEN, A.; MEURER, F. Inclusão de milheto em dietas para alevinos de tilápia-do-nilo formuladas com base na proteína e energia digestíveis. Revista Brasileira de Zootecnia, v. 39, n. 5, p. 950-954, 2010.

BURKET, D.; ANDRADE, D.R.; SIROL, R.N.; SALARO, A.L.; RASGUIDO, J.E.A.; QUIRINO, C.R. Rendimentos do processamento e composição química de filés de surubim cultivado em tanques-rede. Revista Brasileira de Zootecnia, v. 37, n. 7, p. 1137-1143, 2008.

CARVALHO, A.P.; ESCAFFRE, A.M.; TELES, O.; BERGOT, P. First feeding of common carp larvae on diets with high levels of protein hydrolysates. Aquaculture International, v. 5, p. 361-367, 1997.

CHOI, Y.J.; HUR, S.; CHOI, B.; KONNO, K.; PARK, J.W. Enzymatic hydrolysis of recovered protein from frozen small croaker and functional properties of its hydrolysates. Journal of food Science, v. 74, n. 1, p. 17-24, 2009.

COTAN, J.L.V.; LANNA, E.A.T.; BOMFIM, M.A.D.; DONZELE, J.L.; RIBEIRO, F.B.; SERAFINI, M.A. Níveis de energia digestível e proteína em rações para alevinos de lambari tambuiú. Revista Brasileira de Zootecnia, v. 35, n. 3, p. 634-640, 2006.

CREPALDI, D.V.; FARIA, P.M.C.; TEIXEIRA, E.A.; RIBEIRO, L.P.; COSTA, A.A.P.; MELO, D.C.; CINTRA, A.P.R.; PRADO, S.A.; COSTA, F.A.A.; DRUMOND, M.L.; LOPES, V.E.; MORAES, V.E. O surubim na aquacultura no Brasil. Revista Brasileira Reprodução Animal, v. 30, n. 3/4, p. 150-158, 2006.

\section{Conclusões}

Em relação aos diferentes hidrolisados cárneos avaliados, pode-se considerar que o hidrolisado de fígado suíno pode ser utilizado em dietas de surubim do Iguaçu, visando melhorar o desempenho zootécnico desses animais, pois ele proporciona melhores valores de peso e ganho de peso e não afeta os parâmetros bioquímicos do sangue e de composição de carcaça.

CREPALDI, D.V.; TEIXEIRA, E.A.; FARIA, P.M.; RIBEIRO, L.P.; MELO, D.C.; OLIVEIRA, D.A.A.; TURRA, E.M.; QUEIROZ, B.M. Rendimento de carcaça em surubim (Pseudoplatystoma spp.) avaliado por ultrassom. Revista Brasileira de Saúde e Produção Animal, v. 9, n. 4, p. 813-824, 2008.

FEIDEN, A.; SIGNOR, A.A.; DIEMER, O.; SARY, C.; BOSCOLO, W.R.; NEU, D.H. Desempenho de juvenis de jundiás (Rhamdia voulezi) submetidos à alimentação com ração orgânica certificada e comercial. Revista Acadêmica Ciências Agrárias e Ambientais, v. 8, n. 4, p. 381-387, 2010.

FRIES, E.M.; LUCHESI, J.D.; COSTA, J.M.; RESSEL, C.; SIGNOR, A.A.; BOSCOLO, W.R.; FEIDEN, A. Hidrolisados cárneos proteicos em rações para alevinos de kinguios (Carassius auratus). Boletim do Instituto de Pesca, v. 37, n. 4, p. 401-407, 2011.

GARAVELLO, J.C. Revision of genus Steindachneridion (Siluriformes: Pimelodidae). Neotropical Ichtyology, v. 3, n. 4, p. 607-623, 2005.

GOES, E.S.R.; FEIDEN, A.; ZAMINHAM, M.; FINKLER, J.K.; FREITAS, M.A.; BOSCOLO, W.R. Hidrolisados cárneos em rações para alevinos de piavuçu Leporinus macrocephalus. In: II SIMPÓSIO NACIONAL DE ENGENHARIA DE PESCA E XII SEMANA ACADÊMICA DE ENGENHARIA DE PESCA, 2010. Anais... Toledo, 2010. 1 CD-ROM.

HEVRØY, E.M.; ESPE, M.; WAAGB $\varnothing$, R.; SANDNES, K.; RUUD, M.; HEMRE, G.I. Nutrient utilization in Atlantic salmon (Salmo salar L.) fed increased levels of fish protein hydrolysate during a period of fast growth. Aquaculture Nutrition, v. 11, n. 4, p. 301-313, 2005. KUMAR, V.; MAKKAR, H.P.S.; AMSELGRUBER, W.; BECKER, K. Physiological, haematological and histopathological responses in common carp (Cyprinus carpio L.) fingerlings fed with differently detoxified Jatropha curcas Kernel meal. Food and Chemical Toxicology, v. 48, p. 2063-2072, 2010.

LUO, L.; XUE, M.; WU, X.; CAI, X.; CAO, H.; LIANG, Y. Partial or total replacement of fishmeal by solvente-extracted cottonseed meal in diets of juvenile rainbow trout (Onchorhynchus mykiss). Aquaculture Nutrition, v.12, p. 418-424, 2006.

MARTONE, C.B.; BORLA, O.P.; SÁNCHEZ, J.J. Fishery byproduct as a nutriente source for bacteria and archaea growth media. Bioresource Technology, v. 96, p.383-387, 2005.

NASCIMENTO, J.H.P.; VERRESCHI, D.C.; JESUS.R.S. Hidrolisados Protéicos de Peixe em Dietas para Alevinos de Surubim, Pseudoplatystoma coruscans (Agassiz, 1829). Revista Brasileira Higiene Sanitária Animal, v. 2, n. 2, p. 1-5, 2008.

NEVES, R.A.M.; DE MIRA, N.V.M.; MARQUEZ, U.M.L. Caracterização de hidrolisados enzimáticos de pescado. Ciência e Tecnologia de Almentos, v. 24, n. 1, p.101-108, 2004.

OLIVA-TELES, A.; CERQUEIRA, A.L.; GONÇALVES, P. The utilization of diets containing high levels of fish protein hydrolysate by turbot (Scophthalmus maximus) juveniles. Aquaculture, v.179, p.195-2012, 1999.

ÖNER, M.; ATLI, G.; CANLI, M. Changes in sérum biochemical parameters of freshwater fish Oreochromis niloticus following prolonged metal $(\mathrm{Ag}, \mathrm{Cd}, \mathrm{Cr}, \mathrm{Cu}, \mathrm{Zn})$ exposures. Environmental Toxicology and Chemistry, v. 27, n. 2, p. 